\title{
A Preliminary Study of Vocational College Students' English Idioms' Learning Through Translation
}

\author{
LU Qun-hua \\ Jiaxing Vocational Technical College, Jiaxing, China
}

\begin{abstract}
To learn English idioms well is not easy for native speakers, let alone ESL/EFL learners, which is because the meanings of idiomatic expressions cannot be determined through an analysis of their individual word meanings. However, the frequency of figurative languages is very common in English world. So, it is necessary for us to have such knowledge of English idioms in English study. Based on literature review, few studies focused their attention on examining vocational colleges EFL problems in English idioms. Moreover, fewer studies provided quantitative data to demonstrate the problems. Understanding the original texts in one language is the key to accurate translation of another language. Translation may be a good way to examine whether students understand English idioms. Thus, the aim of the present study was to investigate vocational college students' understanding level of English idioms through their translation in order to find how difficult English idioms are for them. Participants were 36 sophomore students who study at Jiaxing Vocational and Technical College. Student's total errors of Chinese translations could be found through the coding as well as the total accurate number of Chinese translations. The findings suggest these students' understanding level of English idioms is not high. It is further supported by the fact that English idioms are difficult and not translated easily from one language to another language.
\end{abstract}

Keywords: English idioms, translation, teachers college students

\section{Introduction}

Idiomatic expressions are even difficult for English native speakers because their meanings cannot be determined through an analysis of their individual word meanings (Chomsky, 1965, 1980; Cooper, 1998, 1999; Levorato \& Cacciari, 1992). For instance, "to kick the bucket or to bite the dust means to die" (Cooper, 1999, p. 233). The figurative interpretation of "shoot the breeze" is "to talk without purpose" (Gibbs, Nayak, \& Cutting, 1989, p. 576). Unlike literal language, English idioms cannot be predicted through their individual word meanings. Thus, English idioms are difficult to understand and acquire, as Cooper (1999) pointed out, "Because figurative meaning is unpredictable, idioms present a special language learning problem for virtually all groups of learners..." (p. 233). In the acquisition of English idioms, Nippold (1991) also argued, "there is no clear point in human development when it can be said that idioms have been mastered" (p. 101).

To master English idioms is hard for L1 learners, let alone ESL/EFL learners. For L2 learners, English idioms are a stumbling block. It is very possible that they not only often feel at a loss in understanding conversations because of a key idiom but also misuse idioms. Buchwald (2000) pointed out that foreigners often misinterpret what Americans say because they take every Americans' saying literally. For

LU Qun-hua, lecturer, master, Foreign Language and Trade Department, Jiaxing Vocational Technical College. 
instance, after he told a foreigner "Why don't you give me a holler?" Two days later he heard this foreigner calling his name from the sidewalk near his office (p. 104). In fact, "give someone a holler" means, "get in touch with someone" rather than "call someone loudly". Although some phrases were made up of simple words, they are still difficult for a very fluent EFL speaker (Bennett, 1994). Thus, English idioms are probably the most problematic thing for ESL/EFL learners to comprehend and interpret in English learning. Nevertheless, few studies investigated whether Chinese EFL learners have the problem of comprehending English idioms or not.

Nevertheless, the type of figurative language is highly used in the daily life in America. According to Levorato and Cacciari (1992), "mass media, textbooks and everyday language represent rich sources of idiomatic speech" (p. 416). Adkins (1968) also pointed out idioms are the basis for understanding the language because they constitute a large part of it. Researchers acknowledged the ubiquitous nature of figurative expression in the everyday experiences in America (Gibbs, 1994; Qualls \& Harris, 1999).

Consequently, it is necessary for us to have such knowledge of how to interpret nonliteral uses of sentences in order to comprehend an English native speaker's message. As Qualls and Harris (1999) asserted that the ability to understand idioms is important to successful communication. They further pointed out the difficult comprehension of English idioms may also lead to communication breakdown for the persons from different language communities. Nippold and Martin (1989) also stressed, "Failure to grasp the meanings of idioms can impinge upon an individual's understanding of language in social, academic, and vocational settings" (p. 59). However, we know little about teachers college students' comprehension of idioms in Taiwan.

Full understanding of text is critically the key to correct translation (ZHOU, 1996; LIN, 1994; ZHANG et al., 1993; ZHANG, 1991; YE, 2000). In other words, it is easy to make translation mistakes without understanding texts completely. For instance, "Let's talk business" is translated into the Chinese sentence, “让 我们来谈生意”; however, it means, “我们来谈正经事吧”. There is big difference between the translation and the original meaning. We can see that the comprehension of this translator is wrong (ZHOU, 1996). In Wu's (2002) study, students' comprehension level of financial text was found through their translation. Thus, translation may be also a good way to test students' comprehension level of English idioms.

Many researchers have studied the acquisition and comprehension of English idioms; however, few studies focused on Taiwanese EFL learners' difficulty in understanding English idioms. Do they see the light on English idioms? Do they have difficulty in comprehending English idioms? In addition, translation is essentially associated with full understanding. Thus, the main purpose of the present study was to investigate teachers college students' understanding level of English idioms through their translation in order to discover whether they have any difficulty with English idioms.

\section{Research Questions}

The research questions underlying the present study were:

(1) To what extent do college students provide accurate Chinese translations of English idioms?

(2) To what extent do college students understand English idioms?

(3) Is there any group of idioms in the present study to cause students' particular problem in understanding?

(4) Do college students have any difficulty in understanding English idioms? 


\section{Literature Review}

\section{Research on Idioms}

For English native speakers, researchers have widely examined the variables affecting the comprehension of English figurative expression such as kick the bucket, cook your goose, and bury the hatchet (Gibbs, Nayak, \& Cutting, 1989). Gibbs and his associates (1989) investigated the role of semantic decomposition in the process of English idioms. Because some idioms are highly decomposable and other idioms are nondecomposable, they "expected that nondecomposable idioms should be processed more quickly than decomposable phrases because expressions such as kick the bucket are lexicalized and should be easier to access from the mental lexicon" (p. 576). The results found that two experiments proved a processing advantage of semantic decomposition. However, one experiment in their study showed that noncomposable idioms were processed more slowly than decomposable idioms (p. 576). Gibbs (1991) further examined the role of semantic analyzability in children's understanding of English idioms. Kindergarteners and first, third, and fourth graders listened to idioms either alone or at the end of short story contexts. The findings indicated younger children (kindergartners and first graders) understood decomposable idioms better than they did nondecomposable ones. Older children (third and fourth graders) understood both decomposable and nondecomposable idioms well in supporting contexts but they interpreted decomposable idioms better than nondecomposable idioms without contexts.

Some researchers studied the familiarity of English idiom comprehension in children and adolescents (Popiel \& McRae, 1988; Schweigert, 1986; Strand \& Fraser, 1979). Strand and Fraser (1979) indicated that easier idioms are possibly those that children frequently encounter and find useful in their natural environments. Idioms have different degrees of the difficulty in comprehension according to their frequency of occurrence in the language (Popiel \& McRae, 1988). Cacciari and Levorato (1989) discovered that children, at the age of seven, were able to understand the meanings of figurative expressions in a rich informational environment. Levorato and Cacciari (1992) moreover investigated the relationship between idiom familiarity (or frequency of exposure) and idiom understanding in children from Grades 1 and 3. Results showed that familiar idioms were easier to understand than unfamiliar idioms for the first graders but that the two types did not make difference for the third graders. Third graders performed better than the younger group on both types of idioms. Thus, they concluded that familiarity plays a minor role in children's comprehension of idioms and only for children who are not yet able to use contextual information.

However, Nippold and Rudzinski (1993) investigated whether familiarity and transparency accounted for the wide differences in idiom difficulty in the developmental study of children and adolescents. Children and adolescents ages 11,14 , and 17 years $(\mathrm{N}=150)$ were asked to explain in writing the meanings of 24 different idioms. Results revealed that performance on the interpretation of idioms improved as subject age increased. High-familiarity figurative expressions were generally easier to interpret than moderate-or low-familiarity expressions. This supports language experience view of idiom familiarity. Easier idioms were also likely to be more transparent. Nippold and Taylor (1995) further examined familiarity of idioms in school-age children and adolescents $(\mathrm{N}=150)$, Grades 5,8 , and 11 . Results indicated that familiarity plays an important role in the development of idiom understanding in youth. Idioms that were higher in familiarity and transparency were easier for youth to comprehend than those that were less familiar and more opaque. This study provides further support for the language experience hypothesis in the development of figurative expression. 
Nippold, Taylor, and Baker (1996) examined the development of idiom understanding in Australian students from Grades 5 and 8. Based on the students' choices of idiom interpretation, results showed that their performance improved as the grade level increased. Idiom familiarity was significantly related to idiom comprehension. This also supports the language experience hypothesis of figurative language development in the previous studies (Nippold \& Rudzinski, 1993; Nippold \& Taylor, 1995). Qualls and Harris (1999) compared African American and European American fifth graders in the study of effects of familiarity on idiom comprehension. This study was conducted to test the language experience hypothesis, the comprehension of high-, moderate-, and low-familiarity idioms. Results showed a significant effect of group on idioms rated as low-familiarity, whereas idioms rated as high-and moderate-familiarity did not distinguish the group. This finding also revealed that a pattern of comprehension was different from the findings in previous studies, based on levels of familiarity (e.g., Nippold \& Rudzinski, 1993).

Some researchers investigated the effect of contextual information on the comprehension of idioms. Ortony, Schallert, Reynolds, and Antos (1978) examined the effects of context on interpreting metaphors and idioms. The subjects were asked to interpret metaphorical and idiomatic phrases or literal phrases. Results showed that subjects took significantly longer to understand metaphorical than literal phrases in the short context condition. "This difference disappeared when the context length was increased" (p. 473). Ackerman (1982) investigated the role of contextual information and the conventional forms of idioms in children's comprehension of idioms. The subjects were asked to interpret idiomatic meanings of the final sentence in the presence of varying linguistic contexts. The results revealed that 6- and 8-year-olds could understand the sentences mainly in idiomatic contexts, whereas the 10-year-olds and the adults could understand the sentences not only in idiomatic contexts but also in literal and neutral contexts. It suggested that younger children rely on idiomatically biasing contexts more than older children. Nippold and Martin's (1989) study, 475 adolescents from age 14 to age 17 were asked to interpret idioms in isolation and context. Results demonstrated that the study did support the idea that linguistic contextual information enhances adolescents' interpretation of idioms. Accuracy for both presentation modes, in isolation and context, gradually improved as the age increased. Nevertheless, even the oldest students had not yet mastered the task in either mode.

In ESL/EFL area, few researchers paid their attention to the studies related to English idioms. However, an ESL/EFL student may learn grammar and acquire sufficient vocabulary, but without knowledge of such idiomatic expressions as "to put out, to get along, to call for, look over", his reading will be slower and his comprehension will suffer (Adkins, 1968). In his study, Adkins (1968) pointed out that Spanish ESL speakers hardly learned English idioms and tended to translate literally from English to Spanish in their reading. Needless to say, they never tried to use those expressions orally in natural conversation. Irujo (1985) examined whether advanced learners of English used the knowledge of their first language in the comprehension and production of English idioms. Results showed that the idioms that were totally different in both languages were harder for them to comprehend and produce than the identical and similar ones. Bennett (1994) discovered that even a very fluent EFL speaker had difficulty with English idioms. Cooper (1999) asserted,

Because of a lower level of linguistic competence in the target language, L2 learners are at a distinct disadvantage in understanding L2 figurative expressions, yet they will meet idioms in all forms of discourse: in conversations, lectures, movies, radio broadcasts, and television programs; in all forms of print, such as newspapers, magazines, and books; and throughout the world of electronic communication. (p. 234) 
Further it also indicated, "Anyone who has tried to learn to speak an L2 sooner or later realizes that idioms are a stumbling block" (p. 258). Buchwald (2000) found that foreigners often misinterpret what Americans say because of misunderstanding English idioms.

\section{Understanding and Translation}

The process of translation can be described in two ways: a psychological process and an operational process. The psychological process is the neuro-psychological theory of translation in finding out how the brain receives and transfers messages, and whether there is a device in the human brain responsible for the conversion of a message from one language to another language (Tan, 1998, p. 332). Tan (1998) further asserted that since science has not yet developed to a stage where the psychological process of translation can be objectively stated, the operational process of translation has attracted a great deal of interest from translation theorists and has been represented in a number of models. For example, there have been the model, the two steps, three-, or four-step models. Commonly accepted in China is a two-step model, i.e., the "understanding-expressing" model. Prevailing in the Western tradition has been a three-stop model: "SL text-meaning-TL text". Last, the four steps of Nida's (1964) model are: "analysis-transfer-restructuring-testing" (Tan, 1998, pp. 332-333). According to these three models, the translator sees a text, understands it and then reproduces it in the target language or goes through a process involving analyzing, understanding, transferring, restructuring, and testing. It is obvious that understanding of original texts in one language is the key to accurate translation of another language in the operational process of translation.

Moreover, translation scholars pointed out that it is easy for Chinese to erroneously translate English texts into Chinese expressions because of misunderstanding (ZHOU, 1996; LIN, 1994; ZHANG et al., 1993; ZHANG, 1991; YE, 2000). For instance, the literal meaning of "hold one's breath" is to stop breathing for a short period. Whereas, the meaning of the figurative expression is "wishful thinking" in this sentence, "I expect the mail to be delivered soon, but I'm not holding my breath" (Liu, 1997). "Have no time for" means "dislike" (Liu, 1997). "Don't cross the bridge till you get to it". The accurate Chinese translation of the sentence is “不必 自寻烦恼”. “Do you see any green in my eye?” It means “你以为我是好欺负的吗?” (ZHANG et al., 1993, p. 63). Obviously, without complete understanding of those figurative expression, it is common for Chinese to translate them into Chinese literally and mistakenly (ZHOU, 1996; LIN, 1994; ZHANG et al., 1993; ZHANG, 1991; YE, 2000).

\section{The Consideration of the Present Study}

English is a world language. "Almost 800 million people now speak English as a first or second language - an increase of about 40 percent in the past twenty years" (Reeves, 2000, p. 84). Liu M. in Taiwan also encourages people to study English or improve their English ability. It further strongly promotes college educators and researchers to help undergraduates increase their English proficiency in order to keep up with modern developments. In addition, Cooper (1998) affirmed that learning to use idioms is extremely critical for achieving command of authentic language. Pollio and his associates (1977) discovered that a person probably would use 20 million idioms through analysis of political debates, taped psychotherapy sessions, and compositions written by students and adults. Therefore, it is emergent for educators or researchers to understand undergraduates' comprehension level of English idioms and help them acquire English idioms in order that they can master English. 
Based on reviewing the studies of idioms, English native speakers have a difficulty in understanding or even using idioms in the daily life (e.g., Gibbs, Nayak, \& Cutting, 1989). It was assumed that English idioms should be much more difficult for ESL/EFL learners. As Cooper (1998) affirmed, "If idioms are difficult to comprehend and acquire for native language learners, they are especially problematic for bilingual and second language learners" (p. 258). Nevertheless, most of the studies on idioms have involved English native speakers (Cooper, 1999). Few studies focused their attention on examining EFL problems in English idioms, especially for Vocational Colleges' EFL learners. In addition, most of them only provided anecdotal data in the demonstration of Chinese EFL learners' problem in understanding English idioms. Thus, the main purpose of the present study was to offer a start point for demonstrating Vocational Colleges' EFL learners' difficulty with English idioms in a quantitative approach.

\section{Methodology}

\section{Participants}

Participants were 36 sophomore students who study at Jiaxing Vocational and Technical College. Sophomores were chosen because they not only have been taking English courses since freshman year but also have chosen English as a minor. Until their graduation they should at least take ten English courses for their requirement. They need to have good English proficiency in order to be qualified employees in the future. Moreover, the class they were taking happened to be a translation class when this study was conducted. Because English idioms are highly frequent in spoken or written language, students should have an opportunity to learn and acquire them in class so that it might help them become proficient in English.

\section{Instrument}

Three groups of idioms were separately chosen from the three stories: "Trouble on Cloud Nine", "Fritz Waller's Big Story, Part I", and "Food for Thought". These three stories were from the book, IDIOMAGIC. This book is one of Studio Classroom's series. The book of stories introduces hundreds of common idioms. John Ryan collected the stories of the book in the year of 1994. The researcher was afraid that only one group of idioms was relatively a small size for the study and the result would be too subjective so that she used three groups of idioms instead of one group of idiom.

In order to attain the purpose of the study, I used students' translation of English idioms to examine their comprehension level of them. The students were divided into three groups according to the translation grade in Mid-term and tests in class in order to make sure that three groups of students were normally distributed. Each group included 12 students. The students in the same group were assigned to translate the same group of idioms into Chinese. One group of idioms from the story, "Trouble on Cloud Nine", was called A group of idioms. Another group of idioms from the story, "Fritz Waller's Big Story, Part I", was called B group of idioms. The last group of idioms from the story, "Food for Thought", was called C group of idioms. These three groups of idioms were presented to students without story contexts because based on the literature review, contextual information possibly increases understanding of idioms (e.g., Nippold \& Martin, 1989). Thus, all students translated 15 English idioms presented in isolation into Chinese in order to test their level of understanding. Before their translation, they were told that these three groups of phrases were idioms since Cooper (1998) pointed out that an idiom can have a literal meaning and figurative meaning. For instance, over the hill can mean on the other side of the hill, but the figurative meaning is to be very old (p. 255). 


\section{Data Collection and Data Analyses}

One independent coder established inter-code reliability with the researcher. The coder has lived in America for nine years. He obtained his M.Ed. degree from the Department of Computer Education. He is a computer consultant in America now. Based on the Chinese translations from the book, IDIOMAGIC (Ryan, 1994), the translation errors were counted. On counting the number of translation errors, the coder and the researcher agreed on $100 \%$ of the judgments. There were three dependent variables collected from students' errors: (1) The number of G1 students' translation mistakes of A group of English idioms: G1Aidiom; (2) the number of G2 students' translation mistakes of B group of English idioms: G2Bidiom; and (3) the number of G3 students' translation mistakes of $\mathrm{C}$ group of English idioms: G3Cidiom. In data analyses, student's total errors of Chinese translations could be found through the coding as well as the total accurate number of Chinese translations. Fifteen divided the total accurate number respectively so that students' comprehension levels of English idioms would be uncovered. In addition, ANOVA was used to test three groups' errors of Chinese translations. When the result was significant, then T-Tests were utilized to compare translation errors between groups in order to check if any particular group of idioms caused problems in students' understanding. Significance levels were set a prior at $\alpha=.05$ for all tests.

\section{Results}

Table 1 summarized three group of students' means and standard deviations of errors in translating English idioms. The first group of students made 11.58 mistakes out of 15 idioms. Furthermore, the second group of students made 13 errors out of 15 idioms. Last, the third group of students made 12.17 mistakes out of 15 idioms. Thus, the result shows that students' translation errors are very high.

Table 1

Means and Standard Deviation of Chinese Translation Errors of English Idioms

\begin{tabular}{llll}
\hline Errors/Groups & $\mathrm{M}$ & $\mathrm{SD}$ & $\mathrm{n}$ \\
\hline G1Aidiom & 11.58 & 1.16 & 12 \\
G2Bidiom & 13 & 1.13 & 12 \\
G3Cidiom & 12.17 & .83 & 12 \\
\hline
\end{tabular}

Means and standard deviations of students' comprehension levels of idioms appeared in Table 2. It reveals that students' level of accurate Chinese translations of English idioms is very low. Thus, it indicates that the students' level of comprehending English idioms is not high.

Table 2

Means and Standard Deviation of Students' Comprehension Levels of English Idioms

\begin{tabular}{llll}
\hline Comprehension level & $\mathrm{M}$ & $\mathrm{SD}$ & $\mathrm{n}$ \\
\hline $\mathrm{G} 1$ & .23 & .07812 & \\
$\mathrm{G} 2$ & .14 & .07412 & \\
$\mathrm{G} 3$ & .19 & .05412 & \\
\hline
\end{tabular}


Table 3

Comparing Three Groups of Chinese Translation Errors of English Idioms

\begin{tabular}{lcccc}
\hline Variance & SS & MS & F & \\
\hline $\begin{array}{l}\text { Source } \\
\text { Translation } \\
\text { Errors }\end{array}$ & 12.7 & 6.08 & 5.49 & .009 \\
\hline
\end{tabular}

The follow-up T-Tests of comparing Chinese translation errors between groups were displayed in Table 4 . The first group of students $(\mathrm{M}=11.58, \mathrm{SD}=1.16)$ made a smaller number of errors than did the second group in translation $(\mathrm{M}=13, \mathrm{SD}=1.13), \mathrm{t}(22)=-3.03, \mathrm{p}=.006$. The second group of students $(\mathrm{M}=13, \mathrm{SD}=1.13)$ had more errors in translation than did the third group $(\mathrm{M}=12.17, \mathrm{SD}=.83), \mathrm{t}(22)=2.06, \mathrm{p}=.05$. There was no significance between the first group of students $(\mathrm{M}=11.58, \mathrm{SD}=1.16)$ and the third group of students in translation mistakes $(\mathrm{M}=12.17, \mathrm{SD}=.83), \mathrm{t}(22)=-1.41, \mathrm{p}=.17$. The result shows that the second group of idioms is much more difficult than the other two groups in causing students' understanding problems.

Table 4

Tests of Comparing Chinese Translation Errors Between Groups

\begin{tabular}{llll}
\hline Errors/Groups & $\mathrm{t}$ & $\mathrm{df}$ & $\mathrm{p}$ \\
\hline G1 vs. G2 & -3.03 & 22 & .006 \\
G2 vs. G3 & 2.06 & 22 & .050 \\
G1 vs. G3 & -1.41 & 22 & .17 \\
\hline
\end{tabular}

\section{Discussion}

The result of the present study shows that English idioms are very difficult for Vocational College students to comprehend and translate into Chinese. Students' translation errors indicate that English idioms present a serious problem for people from other cultures. For example, the figurative meaning of "pull a fast one” is “欺骗某人; 对某人恶作剧” instead of “锦上添花”. Another student translated "have to hand it to someone” into the Chinese phrase, “传递东西”. However, it means “必须对某人表示敬意”. The finding confirms those findings regarding the comprehension of English idioms. As Smitherman (1977) pointed that the understanding and interpretation of idiomatic expressions is intimately linked to one's own culture. Qualls and Harris (1999) further asserted, "Idiomatic expressions are culture-specific" (p. 142). Translation scholars also affirmed that every country has its own idioms related to its own culture and custom; therefore, it is hard for Chinese students to understand English idioms. Mistranslating English idioms is very common for Chinese (Liu, 1997; ZHOU, 1996; LIN, 1994; ZHANG et al., 1993; ZHANG, 1991; YE, 2000). Furthermore, the finding affirms that English idioms are a stumbling block for EFL learners (Bennett, 1994; Cooper, 1998; Buchwald, 2000).

Another finding of the present study is that students usually translate English idioms into Chinese literally. For instance, “the eleventh hour” was translated into “第十一个小时”. The idiom, "get in someone's hair” was interpreted into “拿到某人的头发”. Someone translated “food for thought” into the Chinese phrase, “想要吃 东西”. The idiom, “have one's cake and eat it, too" was mistakenly translated into the Chinese expression, “拿 他的蛋糕来吃” and “take the cake” was inaccurately translated into “拿走这蛋糕”. This result demonstrates Cooper's (1999) finding that using the literal meaning of idiom is a common processing strategy for nonnative 
speakers. It does support the fact that the problem foreigners in America have is that they take everything Americans say literally (Buchwald, 2000).

Moreover, the result reveals that English idioms that are similar to the Chinese expressions are easier for students to comprehend and translate accurately into Chinese. For instance, these idioms were easy for students to understand as follows: “kill two birds with one stone" (一石二鸟), “one's heart is not in something” (心不在 意), and “go in one ear and out the other" (左耳进右耳出). This finding also confirms the finding, “Second language learners make use of their native language when processing target language idioms" (Adkins, 1968; Cooper, 1998).

Additionally, the finding illustrates that when English idioms are more familiar to students, they are easier for them to interpret the figurative meanings of English idioms, such as "a piece of cake" and "easy as pie".

Last, the result discovers that the second group of idioms causes students' problems of comprehension in particular in the present study. Altogether, fourteen students mistakenly interpreted eight idioms in the second group of idioms. In other words, these eight idioms were more difficult for students compared to the other idioms in the same group. The result shows that the degree of difficulty of the English idioms is different. It indicates that students' comprehension might be related to students' familiarity of idioms. Idiomatic familiarity might be one factor to cause EFL students' difficulty in understanding as well as English native speakers.

In conclusion, those findings of the present study demonstrate college students have a serious difficulty in understanding idiomatic expressions. This suggestion is further supported by the fact that English idioms are difficult and not translated easily from one language to another language for EFL learners without full understanding.

\section{Suggestions for Future Research}

Future research could expand on the study in the following:

(1) The number of the students in the present study-36-was small. Other studies might use a larger number of students.

(2) Students had much difficulty in understanding English idioms presented in isolation. Other studies might explore the role of the context in which the English idioms are presented to the subjects. For example, one of my following studies is going to test the effect of the story context on understanding English idioms.

(3) Future studies might examine the relationship between the familiarity of English idioms and comprehension in EFL setting in order to uncover the reasons to cause EFL students' comprehension problems in particular.

(4) Other researchers might investigate English idioms as well as other figurative expression types (e.g., proverbs, or metaphors) in EFL setting.

\section{Conclusion}

Based on the findings of the present study, it is important to teach English idioms in class because college students have difficulty with English idioms. Furthermore, it is better for EFL educators to choose English idioms that are frequently encountered in the target community for authentic use in the daily life. Another suggestion is that EFL educators might use various activities such as listening, reading, or watching movies in order that student could learn more diverse English idioms from different modes. In addition, EFL teachers might design interesting exercises that could help students develop their knowledge about English idioms. Last, 
for the EFL classroom, it is also important for EFL teachers to introduce good idiom books that include interesting facts about the origins of idioms, and tips on how and when to use them (Liu, 1997; ZHOU, 1996; LIN, 1994; ZHANG et al., 1993; ZHANG, 1991; YE, 2000).

\section{References}

Ackerman, B. P. (1982). On comprehending idioms: Do children get the picture? Journal of Experimental Child Psychology, 33 , 439-454.

Adkins, P. (1968). Teaching idioms and figures of speech to non-native speakers of English. Modern Language Journal, 52 , 148-152.

Bennett, B. (1994). When is a "pretty kettle of fish" a "red herring"? Modern English Teacher, 3(2), 19-21.

Buchwald, A. (2000). Don't say "Let's Get Together" to a foreigner. In S. K. Cohen (Ed.), Building reading fluency: Words in focus (pp. 104-105). Singapore: Thomas Learning.

Cacciari, C., \& Levorato, M. C. (1989). How children understand idioms in discourse. Journal of Child Language, 16, $387-405$.

Chomsky, N. (1965). Aspects of the theory of syntax. Cambridge, MA: MIT Press.

Chomsky, N. (1980). Rules and representations. New York: Columbia University Press.

Cooper, T. C. (1998). Teaching idioms. Foreign Language Annals, 31(2), 255-266.

Cooper, T. C. (1999). Processing of idioms by L2 learners of English. TESOL Quarterly, 33(1), 233-262.

Fraser, B. (1970). Idioms within a transformational grammar. Foundations of Language, 6, 22-42.

Gibbs, R. W. (1991). Semantic analyzability in children's understanding of idioms. Journal of Speech and Hearing Research, 34, 613-620.

Gibbs, R. W. (1994). The poetics of mind, figurative thought, language, and understanding. Cambridge: Cambridge University Press.

Gibbs, R. W., Nayak, N. P., \& Cutting, C. (1989). How to kick the bucket and not decompose: Analyzability and idiom processing. Journal of Memory and Language, 28, 576-593.

Gorman-Gand, K. A. (1992). Figurative language: A comprehensive program. Eau Claire, WI: Thinking Publications.

Heringer, J. (1976). Idioms and lexicalization in English. In M. Shibatani (Ed.), Syntax and semantics: Vol. 6: The grammar of causative constructions (pp. 205-216). New York: Academic Press.

Irujo, S. (1986). Don't put your leg in your mouth: Transfer in the acquisition of idioms in a second language. TESOL Quarterly, 20, 287-304.

Katz, J. (1973). Compositionality, idiomaticity, and lexical substitution. In S. Anderson and P. Kiparsky (Eds.), A festschrift for Morris Halle (pp. 357-376). New York: Holt, Rinehart, \& Winston.

Lazar, R. T., Genese A. W., Cynthia B. N., \& Suzanne J. (1989). Elementary school teachers'use of multiple meaning expressions. Language, Speech, and Hearing Services in Schools, 20, 420-430.

Levorato, M. C., \& Cacciari, C. (1992). Children's comprehension and production of idioms: The role of context and familiarity. Journal of Child Language, 19, 415-433.

LIN, P. T. (1994). 中英对译技巧 (Techniques of Chinese and English translation). 台北市: 学习出版公司.

Liu, M. (1997). A workbook for English-Chinese translation. Taipei: Bookman.

Makkai, A., Boatner, M. T., \& Gates, J. E. (1995). A dictionary of American idioms (3rd ed.). Hauppauge, NY: Baron's Educational Series.

Nida, E. A. (1964). Toward a science of translating. Leiden: E. J. Brill.

Nippold, M. A. (1991). Semantic analyzability in children's understanding of idioms. Journal of Speech and Hearing Research, 34, 613-620.

Nippold, M. A., \& Martin, S. T. (1989). Idiom interpretation in isolation versus context: A developmental study with adolescents. Journal of Speech and Hearing Research, 32, 59-66.

Nippold, M. A., \& Rudzinski, M. (1993). Familiarity and transparency in idiom explanation: A developmental study of children and adolescents. Journal of Speech and Hearing Research, 36, 728-737.

Nippold, M. A., \& Taylor, C. L. (1995). Idiom understanding in youth: Further examination of familiarity and transparency. Journal of Speech and Hearing Research, 38, 426-433.

Nippold, M. A., Taylor, C. L., \& Baker, J. M. (1996). Idiom understanding in Australian youth: A cross-cultural comparison. Journal of Speech and Hearing Research, 39, 442-447. 
Ortony, A., Schallert, D. L., Reynolds, R. E., \& Antos, S. J. (1978). Interpreting metaphors and idioms: Some effects of context on comprehension. Journal of Verbal Learning and Verbal Behavior, 17, 465-477.

Pollio, H. R., Barlow, J. M., Fine, H. K., \& Pollio, M. R. (1977). Psychology and the poetics of growth. Hillsdale, NJ: Erlbaum.

Popiel, S. J., \& McRae, K. (1988). The figurative and literal senses of idioms, or all idioms are not used equally. Journal of Psycholinguistic Research, 17, 475-487.

Qualls, C. D., \& Harris, J. L. (1999). Effects of familiarity on idiom comprehension in African American and European American fifth graders. Language, Speech, and Hearing Services in Schools, 30, 141-151.

Reeves, R. (2000). American English: A world language. In S. K. Cohen (Ed.), Building reading fluency: Words in focus (pp. 84-85). Singapore: Thomas Learning.

Ryan, J. (Ed.). (1994). Idiomagic. Taipei: Studio Classroom.

Schweigert, W. A. (1986). The comprehension of familiar and less familiar idioms. Journal of Psycholinguistic Research, 15, $33-45$.

Smitherman, G. (1977). Talking and testifying. Boston, MA: Houghton Mifflin.

Strand, K. E., \& Fraser, B. (1979). The comprehension of verbal idioms by young children (Unpublished paper, School of Education, Boston University).

Tan, Z. (1998). Components of translation theory. In S. Jin (Ed.), Conference on translation: Studies in translating into Chinese (pp. 327-336). Hong Kong: The Chinese University of Hong Kong.

Wu, S. (2002). Examining the role of schemata in reading comprehension through translation. In Proceedings of the Nineteenth International Conference on English Teaching \& Learning in the Republic of China (pp. 457-466). Tapei: Crane Publishing Co., Ltd..

YE, Z. N. (2000). 英汉翻译理论与实践 (The theory and practice of English and Chinese translation). 台北市: 书林出版公司. ZHANG, D. C. (1992). 实用词汇学 (Practical English lexicology). 辽宁: 辽宁出版社.

ZHANG, P. J., et al. (1993). 修辞学: 理论与实践 (Rhetoric: Theory and practice). 北京: 外语教学与研究出版社.

ZHOU, Z. X. (1996). 现代英语词汇学概述 (An introduction to modern English lexicology). 北京: 北京师范大学出版社. 